Version of Record: https:/www.sciencedirect.com/science/article/pii/S2468125319301190

Manuscript_bc7ee289a9b377bc8061847dba9469cf

\title{
A Global Scientific Strategy to Cure hepatitis B.
}

Revill PA, Chisari FV, Block JM, Dandri M, Gehring, AJ, Guo H, Hu J, Kramvis A, Lampertico P, Janssen HLA, Levrero M, Li W, Liang TJ, Lim SG, Lu F, Penicaud MC, Tavis JE, Thimme R, Members of the ICE-HBV Working Groups, ICE-HBV Stakeholders Group Chairs, ICE-HBV Senior Advisors, and Zoulim F.

\section{Corresponding Author}

Fabien Zoulim Fabien.zoulim@inserm.fr 


\section{Abstract}

Today, more people die from chronic hepatitis $B(\mathrm{CHB})$ virus infection than from TB, HIV or malaria. The International Coalition to Eliminate Hepatitis B (ICE-HBV) is a coalition of experts dedicated to accelerating the discovery of a cure for CHB. Following extensive consultation with more than 50 scientists from across the globe, as well as key stakeholders including people affected by HBV, we have identified the gaps in current knowledge and the new strategies and tools that are required to achieve HBV cure. We believe that research must focus on the discovery of interventional strategies that will (i) permanently reduce the number of productively infected cells and/or permanently silence the cccDNA in those cells, and (ii) stimulate HBV-specific T cells and the production of neutralizing antibodies to prevent viral spread to uninfected cells, thus mimicking spontaneous resolution of acute HBV infection. There is also a pressing need for the establishment of repositories of standardised HBV reagents and protocols that can be accessed by all HBV researchers throughout the world. The HBV cure research agenda outlined in this position paper will contribute markedly to the goal of eliminating hepatitis B virus (HBV) infection worldwide. 


\section{Introduction}

Hepatitis B virus (HBV) is a major global public health threat with over 292 million people worldwide ${ }^{1}$ chronically infected and over 887,000 deaths per year ${ }^{2}$. Chronic hepatitis B (CHB) causes almost $40 \%$ of hepatocellular carcinoma, which is the $2^{\text {nd }}$ leading cause of cancer-related mortality worldwide ${ }^{3}$. The current prophylactic vaccine has no impact on established chronic infection. Available treatments suppress viral replication but they are not curative largely due to (i) the persistence of the viral covalently closed circular DNA (cccDNA) transcriptional template in infected hepatocytes and (ii) the failure of chronically infected patients to mount an immune response that is sufficiently robust, functional and sustained to clear the infection ${ }^{4}$. Thus, in most cases, treatment must continue for life; yet even successfully virally-suppressed patients may still develop liver cancer, especially if their livers are cirrhotic ${ }^{5}$.

Inexplicably, despite the huge human and economic toll of $\mathrm{CHB}^{3}$, $\mathrm{HBV}$ research remains largely underfunded $^{6}$, to the point of recently being compared to a neglected tropical disease ${ }^{7}$. Given recent scientific progress and the momentum created by hepatitis $C$ virus cure discoveries, and the immense public health impact of $\mathrm{CHB}$, we believe that governments, foundations, industry and academic research institutions throughout the world, can and should join forces and work together to accelerate HBV cure research.

ICE-HBV is an international, independent, research-based forum created in 2016 to accelerate HBV cure research. ICE-HBV aims to coordinate, promote and foster collaborative partnerships working towards a HBV cure and the alleviation of suffering for all persons living with $\mathrm{CHB}^{8}$. Following an inclusive nomination process, ICE-HBV formed international multidisciplinary scientific working groups consisting of leaders in HBV virology, immunology, technology and clinical research, who have collaborated to identify current strengths in the HBV field that can be built upon, as well as knowledge gaps that must be addressed to achieve cure. The strategy presented here is the result of a two year-long process, which involved over 50 scientists from 5 continents with input from key HBV research stakeholders from 21 countries*i. Through this process, we are proposing a strategic and collaborative HBV research agenda to advance the discovery of a safe, affordable, scalable and effective CHB cure, accessible to all within the foreseeable future.

HBV Replication Cycle (Figure 1). Following viral entry via binding of the preS1 domain of the large envelope protein to the sodium-taurocholate co-transporting polypeptide (NTCP) receptor ${ }^{9}$ on the hepatocyte plasma membrane, the viral and cellular membranes fuse to release the nucleocapsid, which is transported into the cell nucleus, where it disassembles to release its cargo of partially doublestranded genomic viral DNA. The host DNA repair machinery ${ }^{10}$ then converts the incoming DNA to cccDNA molecules that are packaged into chromatin-like minichromosomes by histone and nonhistone proteins $^{11,12}$ whereupon it acts as the HBV transcriptional template and long-lived reservoir in the hepatocyte nucleus ${ }^{11}$. The $3.2 \mathrm{~kb} \mathrm{HBV}$ genome is organised into 4 overlapping but frame-shifted openreading frames (ORFs) encoding the core protein ( $\mathrm{HBCAg}$, nucleocapsid); Polymerase $(\mathrm{P})$; the precore protein, which is processed to secreted hepatitis $B$ e antigen $(\mathrm{HBeAg})^{13}$; hepatitis $B$ surface antigens (HBsAg consisting of the large, medium and small envelope proteins); and the $\mathrm{X}$ protein (HBX). A number of virus encoded promoter and enhancer elements promote transcription of 5 major mRNAs, namely pregenomic (pgRNA, also the core mRNA), precore mRNA, preS1 and preS2/S mRNA and HBx mRNA) that are translated into the aforementioned seven viral proteins. The pgRNA is encapsidated with $P$ and 
reverse transcribed into DNA. Following viral DNA synthesis mature nucleocapsids are either packaged with envelope proteins to be exported as infectious virions, or recycled back to the nucleus for cccDNA replenishment.

There are still many gaps in our understanding of the HBV replication cycle that are major barriers to HBV cure research, particularly concerning the biogenesis, homeostasis and turnover of the cccDNA reservoir. However, recent technological advances such as the discovery of the NTCP HBV entry receptor ${ }^{9}$, have led to the development of additional cell culture models that, together with other available systems (primary human hepatocytes, HepaRG cells, transient transfection systems, stably transformed cell lines, iPSC-derived hepatocyte-like cells) and the use of humanised mice, permit interrogation of the complete HBV replication cycle. These developments make it feasible to systematically study the mechanisms that control the biogenesis, homeostasis and decay of the cccDNA transcriptional template, and to use that information to identify vulnerabililites in cccDNA machinery that could in turn be exploited to eradicate HBV from infected cells.

In addition to the viral cccDNA reservoir that is not targeted by current therapies, CHB persistence is also the result of the failure of the immune response to eliminate infected cells, and / or protect noninfected cells from infection.

\section{Chronic Hepatitis B - CHB and resolution of infection.}

In the absence of vaccination, over $90 \%$ of persons infected in infancy will progress from acute hepatitis to life-long chronic infection. In contrast, over $90 \%$ of people infected in adulthood will resolve the infection, due to robust immune responses that eliminate infected cells and produce neutralizing antibodies that provide life-long protection. Once chronic infection is established, patients are exposed to significant risk of liver disease including chronic hepatitis, cirrhosis and hepatocellular carcinoma. The natural history of chronic HBV infection usually consists of up to 5 stages ${ }^{14}$, which differ in the level of viral replication, viral antigen expression and inflammatory activity in the liver.

Although only approximately $1 \%$ of chronically infected individuals per year mount an effective immune response to control $\mathrm{CHB}$ infection, spontaneous resolution of acute and chronic hepatitis $\mathrm{B}$ proves that immune control of HBV infection is possible. However, the clinical resolution of a chronic infection and / or of acute hepatitis does not mean complete eradication of the virus, as small numbers of cccDNApositive infected hepatocytes can persist in these subjects ${ }^{15-17}$ and may be the source of viral reactivation during immune suppression ${ }^{18}$. Thus, an unknown number of the 2 billion people alive today, who have resolved previous HBV infection, maintain a viral cccDNA reservoir in their liver. This is demonstrated through the emergence of $\mathrm{CHB}$ infection in people who were infected and initially recovered from HBV infection but in whom the virus reactivated when they were exposed to therapies inducing immune suppression for other medical conditions ${ }^{18}$. We believe that improving our understanding of the biogenesis and homeostasis of HBV cccDNA is urgently required if we are to develop strategies to eliminate it from infected cells, or control its expression.

\section{Immunize, Test and Treat}

Before CHB can be cured, we need to know who is infected and their stage of disease. According to the World Health Organisation (WHO), of the estimated 292 million people living with HBV infection, only $10 \%$ knew their HBV-status in $2015^{1}$, and that most people living with chronic infection are unaware of their very serious health problem. Indeed, of those diagnosed, only $5 \%$ of the 94 million treatment 
eligible carriers receive treatment ${ }^{1}$. The WHO aims to eliminate viral hepatitis as a major public health threat by $2030^{19}$ and while increasing preventative vaccine coverage is the main cornerstone of this global effort to achieve elimination, the WHO also proposes an increase of the proportion of eligible persons treated for $\mathrm{CHB}$ from the current levels of $8 \%$ worldwide, to $80 \%$. This will require a concomitant increase in global HBV testing worldwide. Priority should be given to development of rapid point-of-care (POC) tests for use in low and middle income countries, where HBV is highly endemic. Since there are already effective treatments that have a marked impact on HBV replication and liver disease, increased efforts must be made to improve their access globally. Large-scale accessible diagnosis and treatment facilities in low and middle income countries should be established to reduce mortality and ensure HBV cure preparedness ${ }^{20}$, while investing in the meantime in HBV cure strategies, which could allow important cost-savings for health systems in the long-run. ${ }^{21}$

Current treatments are limited to nucleos(t)ide analogues (NUCs), which are direct acting antivirals that block DNA synthesis ${ }^{22}$ and to interferon-alpha (IFN- $\alpha$ ). IFN- $\alpha$ produces its antiviral effects by multiple mechanisms, including direct suppression of RNA and protein production in infected cells ${ }^{23}$, inhibition of HBV DNA replication by blocking nucleocapsid assembly ${ }^{24}$, as well as immunomodulatory activity, such as the activation of NK cells and T cells that can target HBV infected cells using cytolytic and noncytolytic mechanisms ${ }^{25-27}$. Thus in a small subset of patients, IFN- $\alpha$ treatment can result in cure. In contrast, NUCs only inhibit HBV genome replication, have minimal effect on the immune response or the cccDNA mini-chromosome reservoir, and are not curative.

\section{Monitoring \& Prevention of Cancer.}

Current antiviral therapies reduce but do not eliminate the risk of liver cancer. As curative therapies are developed, it will be important to monitor patients for progression to liver cancer, even if they have been cured of chronic HBV infection. This is particularly important for patients with cirrhosis, generally thought to be most at risk for development of liver cancer; however, certain HBV subgenotypes, such as the African A1 and Alaskan F1b are strongly associated with liver cancer in the absence of underlying cirrhosis $^{28}$. While studies, such as the REVEAL study ${ }^{29}$, have identified HBV-related factors associated with increased likelihood of progressing to liver cancer (high viral load, HBeAg positivity, genotype C, and failure to clear $\mathrm{HBsAg}$ prior to age $50^{30}$ ), there are currently no predictive biomarkers, which accurately predict the onset of cancer in the setting of HBV infection. Even though the cure of infection is likely to reduce the likelihood of developing liver cancer, the direct impact of integrated HBV DNA and the viral proteins, such as the HBsAg and HBx expressed from integrants on cellular gene expression and hepatocyte homeostasis, will need to be carefully considered. Accordingly, new markers that predict the likelihood of progression of chronic HBV infection, with or without cirrhosis, to liver cancer should be developed.

\section{Definitions of HBV cure.}

Discussions about HBV cure are complicated by the need to consider curing both the infection and the associated liver disease.

\section{Cure of viral infection}

Previous discussions of HBV cure have focused mainly on curing the infection, either by eliminating the virus (complete cure), or by controlling the virus and/or by inducing host immune responses to eliminate the infection and prevent viral spread (functional cure) ${ }^{8,31,32}$. A recent joint AASLD-EASL workshop on HBV treatment endpoints further defined complete cure as "sterilising with undetectable HBsAg in serum and eradication of HBV DNA including intrahepatic cccDNA and integrated HBV DNA". Functional cure was defined as "sustained, undetectable HBsAg and HBV DNA in serum with or without seroconversion to hepatitis B surface antibody (anti-HBs), with the persistence of low amounts 
intrahepatic ccCDNA and HBV DNA intergration" (Box 1). A third definition was also proposed (partial cure), defined as "detectable HBsAg but persistently undetectable HBV DNA in serum after completion of a finite course of treatment". Since it is currently not possible to eradicate the HBV cccDNA minichromosome reservoir or integrated HBV DNA from every infected cell, functional cure is more likely to be achievable, at least initially. Indeed, "complete sterilising cure" is yet to be observed naturally in any person living with chronic HBV, nor in persons who have recovered from transient acute HBV infection, and seems unlikely to be achievable therapeutically, at least in the short term.

It is questionable whether current therapies could replicate spontaneous recovery from acute hepatitis B. Studies in chimpanzees showed that in resolution of acute HBV infection, almost all infected hepatocytes are eliminated by the CD8+ T cell response ${ }^{33}$, although HBV is also cleared by noncytopathic mechanisms ${ }^{34}$. A very small proportion of infected cells remain, with infection of new cells prevented by anti-HBs ${ }^{35}$. Such resolution and control of HBV infection has occurred naturally in millions of individuals with acute infection. Although this is rarely achieved by the currently available treatments in persons with $\mathrm{CHB}$, it does occur and indicates that HBV needs not be totally eradicated to achieve lifelong viral control by a sustained cellular and humoral immune response. With this background, we believe that the ideal aim of a curative therapeutic regimen for chronic HBV infection should be to induce resolution similar to that observed in acute or CHB resolvers, as long as this can be done in a safe manner.

\section{Remission of liver disease}

The clinical goal of CHB remission is the resolution of residual liver injury including disappearance of inflammation, prevention of fibrosis progression, reversal of fibrosis and cirrhosis, prevention of liver failure and reduction of the risk of developing $\mathrm{HCC}^{32}$, following completion of a finite course of treatment. Great progress has been made in this regard with the latest generation NUCs demonstrating reversal of fibrosis and reduced likelihood of progression to HCC in many, but not all, patients ${ }^{36,37}$. However treatment is long term and a high priority of curative treatments is that treatment be finite, yet meets the goals of disease remission. Remission in early $\mathrm{CHB}$, where no fibrosis is yet present, is analogous to a person who clears acute HBV infection, but retains HBV cccDNA in some of their hepatocytes- there is no evidence of ongoing liver disease, but the viral reservoir is still present, albeit at very low levels tightly constrained by the humoral and cellular immune responses. Although the remission of liver disease in $\mathrm{CHB}$ does not preclude potential reactivation of disease, it largely meets the societal goal of cure, namely the prevention of adverse outcomes, restoration of health and prolongation of life expectancy after cessation of therapy, elimination of transmission risks, and removal of stigma associated with having a chronic communicalble disease ${ }^{38}$, all of which should be the guiding principles in the ultimate adoption of a definition.

As a result of the academic and industrial efforts to identify viral targets for drug discovery, a number of drugs are being evaluated in pre-clinical models or are in the first phases of clinical development ${ }^{39}$ (Figure 2). These include drugs interfering with viral entry, drugs or other methods targeting cccDNA or viral RNA, novel polymerase or ribonuclease $\mathrm{H}$ inhibitors, capsid assembly modulators, drugs interfering with $\mathrm{HBx}$ function, drugs targeting viral and $\mathrm{HBsAg}$ egress or agents affecting the viral proteome (eg siRNA and RNA destabilizers) (Figure 2). Some of these compounds appear promising, with marked reductions in $\mathrm{HBV}$ viral load and/or circulating $\mathrm{HBsAg}$, and the emergence of anti-HBs, but to date none seem to be capable of curing HBV infection on their own ${ }^{8,31}$. Except for CRISPR/Cas9, none of these approaches directly target the HBV cccDNA reservoir, but it will be important to evaluate these approaches in combination, to determine their effectiveness in the kinetics of cccDNA clearance or in their capacity to improve the restoration of antiviral immune responses. Earlier attempts to boost innate immunity and adaptive immune responses did not lead to improved cure rates, as defined by 
HBsAg loss. It is therefore critical to design drug combinations with the aim that they are curative. To this end, following extensive discussion among the ICE-HBV working groups, we have prioritized the research necessary to achieve HBV cure and the tools that will be required to achieve this goal. These are described in the context of key concepts that should be addressed to eliminate HBV from infected cells and induce effective immune control.

We believe that research efforts should focus on reducing the number of cccDNA molecules per cell and the number of cccDNA-containing cells, and on inducing HBV-specific immune responses to achieve what the host is capable of achieving during the resolution of infection, namely profound reduction of the number of infected cells and induction of $\mathrm{HBV}$-specific immune responses that prevent viral spread from those that remain infected. This needs to be done in a manner that is safe, durable and affordable. This will require increased efforts to improve our understanding of the biogenesis, homeostasis transcriptional regulation and decay of the viral cccDNA reservoir ${ }^{10}$, and factors required to induce host immune responses that control and/or eliminate HBV infection in persons with CHB (Figure 2). However it is also important that research continues to gain knowledge about many other aspects of the HBV replication-cycle, including viral entry and uncoating, mechanisms regulating cccDNA activity, gene expression including mRNA translation and splicing, packaging of pgRNA and its reverse transcription forming the main replication complexes, subviral particle formation, and viral egress.

To achieve our goal of HBV cure, ICE-HBV proposes two strategies, namely (i) curing of HBV infection without killing infected cells and (ii) inducing immune control to safely eliminate infected cells. Each of these approaches will need to be underpinned by coordinated clinical studies to advance HBV cure. A detailed descrtiption of each of these strategies is presented below.

\section{Strategy 1. Curing HBV infection without killing infected cells \\ Background}

It has been more than 50 years since the discovery of the Australia antigen ${ }^{40}$, now known as $\mathrm{HBsAg}$. The discovery of the HBV entry receptor NTCP in $2012^{9}$ revolutionized our ability to study in vitro the HBV replication cycle from infection to egress, and the development of new animal models that permit studies of immunopathogenesis ${ }^{41-43}$ and preclinical antiviral evaluation. However, these models still have considerable limitations, and important gaps in our understanding of the HBV replication cycle and the host immune response (see Strategy 2) must be addressed in order to expand the exploitable vulnerabilities in the replication cycle that can be targeted therapeutically to cure the infection.

\section{Targeting the cccDNA mini-chromosome reservoir.}

The HBV cccDNA mini-chromosome reservoir in the nucleus of infected hepatocytes is the single most important barrier to curing chronic HBV infection. We suggest that research directed towards elimination of cccDNA or permanently silencing cccDNA transcription should be prioritized.

\section{cccDNA elimination.}

cccDNA elimination will be the most direct and efficient strategy to cure chronic HBV infection. Current antiviral drugs do not eliminate cccDNA even after prolonged treatment either in patients or experimental cell culture or animal models. The observation that cytokine administration including IFN- $\alpha$ may induce APOBEC dependent deamination of viral DNA ${ }^{44-46}$ has led to considerable discussion of whether this could lead to a substantial decrease of cccDNA in infected hepatocytes ${ }^{47-49}$. Approaches that directly target ccCDNA such as CRISPR/Cas9 ${ }^{49}$ or other gene editing methodologies ${ }^{50}$ may suffer from issues including hepatocellular delivery, off-target effects, and the likelihood that they will also cleave chromosomally integrated HBV DNA and thus trigger unpredictable consequences of chromosomal DNA recombination. Because of these dangers and difficulties, approaches that target 
viral and/or host proteins that are critical for cccDNA formation, stability and expression (e.g HBx) must be further explored. This will require an intense and coordinated effort to discover the fundamental biochemical, cellular and physiological basis of cccDNA production, maintenance and turnover about which very little is known of all aforementioned limitations encountered to date. However, now that it is possible to study the complete $\mathrm{HBV}$ replication cycle, we believe these studies are imperative because cccDNA elimination is the only strategy that has the potential to definitively produce a safe, durable cure of HBV infection.

\section{cccDNA silencing.}

Since cccDNA is not completely eradicated during spontaneous or treatment-induced resolution of acute or chronic infection ${ }^{51}$, it is not likely that total eradication of cccDNA will be achievable pharmacologically. Transcriptional silencing of the residual pool of cccDNA remaining after most of the cccDNA is eliminated and/or antibody-mediated prevention of virus spread from the remaining infected cells (discussed below) will probably also be necessary. While modification of epigenetic control of cccDNA by "general" epigenetic modifiers would likely be too risky in terms of potential adverse events on cell homeostasis, other strategies targeting viral factors involved in the regulation of cccDNA transcriptional activity should be pursued. Transcriptional control of cccDNA expression may be achieved by targeting the HBx protein which is critical for cccDNA expression and/or stability ${ }^{52-55}$. Greater insight into the role of $\mathrm{HBx}, \mathrm{HBc}^{56}$ and other viral proteins in the control of cccDNA homeostasis is thus mandatory. The "Structural maintenance of chromosomes 5/6" (Smc5/6) complex is a host restriction factor that in the absence of HBx protein, represses cccDNA expression ${ }^{57-59}$. It has recently emerged that $\mathrm{HBx}$ promotes ccCDNA transcription by hijacking cellular DDB1-containing E3 ubiquitin ligase to target the Smc5/6 complex for degradation ${ }^{57}$. Therefore therapeutic approaches targeting the HBx-DDB1 binding interaction are also worthy of investigation. Post-transcriptional control of cccDNA or integrated HBV DNA expression can be achieved using RNA interference (RNAi) and this is currently being pursued as well with promising results ${ }^{60,61}$. The overlapping nature of the HBV genome suggests that RNAi should impede expression of all HBV transcripts, and it has recently been shown that truncated forms of transcripts derived from integrated viral DNA can also be targeted $^{60}$. There is also a pressing need for the development of in situ, single-cell, single-molecule, live-cell assays, to visualize the localization and trafficking of $\operatorname{cccDNA}{ }^{62,63}$, and $\operatorname{cccDNA}$-dependent surrogate reporter cell systems for high throughput screening of cccDNA inhibitors ${ }^{64-66}$.

\section{New Models are required}

Although it is now possible to interrogate the complete HBV replication cycle in cell culture, some limitations of the current models still remain. For example, most studies to date have been limited to HBV genotype $D$, the only genotype for which stably transformed cell lines are readily available to produce HBV, at sufficient multiplicity of infection for downstream experiments. In addition, the transformed nature of hepatoma cells means that they do not fully reflect primary liver cells. Although primary human hepatocytes (PHHs), the natural target cells for HBV infection in vivo, are available and support the complete HBV replication cycle, and are presumably more physiologically relevant to hepatocytes in the liver, their use has limitations. They require polyethylene glycol (PEG), dimethylsulfoxide (DMSO) and high amounts of input virus for infection; they are expensive; they have a limited polarisation and life-span in vitro; and batch to batch variations affect infection efficiency and responses to infection ${ }^{67}$.

In vitro models that would eliminate the need for PEG and provide consistency and uniformity of infection from lab to lab over time are needed to accelerate the discovery process and to confirm the reproducibility of promising new data. Systems that have the chance of satisfying these criteria include human hepatocyte-like cells (HLC) differentiated in vitro from embryonic stem (ES) or induced 
pluripotent stem cells (iPSCs) ${ }^{68-70}$ and 3D microfluidic liver cultures, which permit analysis of the complete HBV replication cycle ${ }^{71}$. However all available HBV infection systems only support limited viral spreading in the cultures. Culture systems that support robust amplification of HBV are needed.

In addition, none of the current animal models for HBV infection is optimal ${ }^{67}$, especially in the context of HBV cure research. Despite the existence of immune-deficient humanised mouse models permitting studies on HBV infection and spreading in vivo, as well as to evaluate the efficacy of direct antiviral compounds in HBV infected primary human hepatocytes, immunocompetent mouse models that are susceptible to HBV infection are only now starting to come online. Humanised mouse models will also enable studies on long term effects of drugs on cccDNA maintenance and loss in non-dividing vs. dividing hepatocytes ${ }^{72}$. Further development of double humanized mouse models (liver and immune system) will permit studies of immune mediated clearance ${ }^{41,42,73}$. Breaching the current intracellular block to HBV infection and cccDNA formation in mouse hepatocytes ${ }^{74}$ would generate a small animal model enabling analysis of the immune response to HBV that may facilitate immune-mediated cccDNA elimination and control, similar to clearance of acute HBV infection. Thus, we believe that the further development of humanized mouse models amenable to $\mathrm{HBV}$ infection should receive high priority because of their great potential to enable studies of mechanisms regulating cccDNA metabolism and clearance.

\section{Nonhuman Primate Models of HBV Infection}

With the loss of the chimpanzee model of HBV infection, the only primate model available to the HBV research community is the tree shrew (Tupaia belangeri chinensis) ${ }^{75,76}$. Research with this model, however, is severely limited by the absence of a deep portfolio of Tupaia-based reagents for virological and immunological analysis. However, the recent discovery that HBV uses NTCP as its receptor, raised the possibility of creating a macaque model for HBV infection by expressing human NTCP on macaque hepatocytes after infection with recombinant AAV vectors, leading to HBV infection for at least 6 weeks ${ }^{77}$. If improved, this model has the potential to not only better understand the immunobiology and pathogenesis of HBV infection and test immunomodulatory approaches to cure chronic HBV infection, but also to study the therapeutic potential of HBV-targeted drugs, including those that target the cccDNA. A macaque model would benefit immediately from the wealth of information and reagents that have been developed during the use of macacques to study Simian Immunodeficiency Virus (SIV) immunobiology and pathogenesis ${ }^{78}$. Thus, we believe that the establishment of a human NTCP transgenic macaque model should be of high priority for the HBV cure research community and for international governmental research funding agencies interested in or committed to curing chronic HBV infection.

Since all current experimental models have limitations, and differences between HBV and HBV-related viruses have emerged, it is likely that observations previously made with HBV-related viruses require confirmation using HBV and human hepatocytes ${ }^{79}$. The research priorities and tools required for HBV elimination are shown in Box 2. 
Strategy 2. Inducing immune control to safely eliminate HBV infected cells.

\section{Background}

There is consensus that a complex interplay of innate and adaptive immune responses is essential for viral clearance and a failure of these responses can result in liver pathogenesis. CD8+ $T$ cells are the main effector cells that eliminate the virus by cytolytic and non-cytolytic effector functions ${ }^{33,34}$. However, sufficient CD4 T cell help as well as the production of neutralizing anti-HBV envelope antibodies are required for protective immunity ${ }^{80}$. A major effort has been made to compare the efficient integrated response resulting in HBV clearance of acute infection to the dysregulated response observed in chronic HBV patients. This knowledge has led to the development of the first generation of immune-based therapies and a second generation of therapeutic vaccines entering Phase I \& Phase II clinical trials.

\section{Current Immunotherapies for chronic HBV infection}

Key points of immune regulation that can be targeted for therapy have been identified in studies performed in animal models and HBV infected patients. Injection of ligands targeting Toll-like receptors (TLRs) or RIG-I leads to suppression of viral replication in HBV mouse models ${ }^{81,82}$. This observation has led to the development of drugs targeting TLR-7 ${ }^{83}$, TLR-8 and RIG-I ${ }^{84}$ for use in chronically HBV infected patients. Numerous experiments have revealed that blocking inhibitory receptors can enhance expansion and function of HBV-specific T cells, both in vitro ${ }^{85-89}$ and in vivo $0^{90,91}$. This has motivated the use of anti-PD-1/PD-L1 antibodies for phase I studies in chronically HBV infected patients. Furthermore, IL-12 apears critical to restoring $T$ cell expansion and function in chronic infection ${ }^{92}$. This has led IL-12, or adjuvants inducing IL-12, to be incorporated into the new generation of therapeutic vaccines for chronic $\mathrm{HBV}^{93}$.

It is encouraging that immunological observations have translated to new experimental therapies. Now, a critical step is to ensure proper immunological evaluation of these strategies to improve their efficacy for future generations of immunotherapy. In addition, continued investigation into the dysregulation of antiviral responses in HBV infection is key to expand the repertoire of immune-based therapies. There has been integration of data on networks of $T$ cell exhaustion mechanisms and the extent to which $T$ cell functionality can be restored as key to effective $T$ cell-based therapies. Since anti-HBs is considered the clinical indicator of HBV resolution, we need a better understanding of the role of $B$ cells and neutralizing antibody response in the natural history of chronic hepatitis $B$ and how they can be effectively enhanced. Mounting evidence for organ-specific immunity necessitates analysis of the liver environment ${ }^{94-96}$. In addition, accurate quantification of the number of infected hepatocytes in chronic HBV patients is important to avoid immune-related toxicity (Box 3). Below, we have highlighted areas of research that are central to addressing these knowledge gaps in order to improve the application of immune-based therapies.

\section{Methodology to improve ex vivo analysis of HBV-specific immunity.}

Compared to chronic infection with $\mathrm{HCV}$, the frequency of virus-specific peripheral blood T cells in $\mathrm{CHB}$ patients is 10 - to 100 -fold lower ${ }^{97}$, often undetectable using standard assays directly ex vivo. Thus, better and more sensitive assays or novel strategies for ex vivo measurement of HBV specific immunity in peripheral blood and liver are needed, e.g. to correlate HBV-specific immunity with stage of disease, responses to immunotherapy and antiviral drugs. They are also needed to define biomarkers that best identify patients who can safely stop antiviral therapy and reflect intrahepatic immunity in the peripheral blood. 
Similarly, novel approaches are needed to study the comprehensive phenotypic and functional characteristics of the intrahepatic $T$ cell responses using limited number of cells from individual biopsies. This data needs to be compared to responses in the blood and then applied as immunebased biomarkers that predict or reflect viral control and inflammation. This comparison needs to be performed in chronically HBV infected patients at different stages of the disease. In addition, assays that allow the analysis of $T$ cells of different epitope specificity need to be further developed to overcome limitations imposed by pentamer/tetramer staining that only partially reflect the overall anti-viral immune response.

\section{Mechanisms of $H B V$-mediated $T$ cell exhaustion and recovery}

HBV persistence is associated with CD8+ T cell exhaustion and (to a lesser extent) with viral escape. Persistent exposure to high antigen loads and antigen presentation by hepatocytes play a key role in

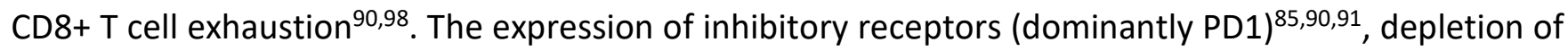
amino acids (e.g. arginine and tryptophan) ${ }^{99}$ and mitochondrial alterations ${ }^{100}$ contribute to $\mathrm{T}$ cell dysfunction (Fig 3). In addition, lack of CD4+ T cell help ${ }^{80,101}$, immunosuppressive cytokines ${ }^{102}$, regulatory $\mathrm{T}$ (Treg) cells ${ }^{103}$, granulocytic myeloid-derived suppressor cells (MDSCs) ${ }^{104}$, and NK cells ${ }^{105}$ also contribute to $\mathrm{CD} 8+\mathrm{T}$ cell failure ${ }^{26,106}$. However, the relative contribution of the different mechanisms to $T$ cell exhaustion are not well characterised and should be actively pursued. Also, whether functional T cell restoration is possible, and if so, how much restoration is required for HBV control is not fully understood. Understanding these aspects will refine our targets to restore $\mathrm{T}$ cell functionality and improve immunotherapy.

Comprehensive analysis of the immune responses of chronic active and inactive HBV infected patients (+/- antiviral therapy), resolved HBV patients, chronically HBV infected patients with HBsAg loss and vaccinated healthy individuals will help define the level of immune function/reconstitution needed for viral control. Recent evidence suggests we need a better understanding of metabolic immune regulation, how this relates to overt, detectable inhibitory receptor expression in immune cells and how this is linked to a broader profile of immune dysfunction. To evaluate the efficacy of checkpoint blockade, the possibility that differential baseline expression of inhibitory molecules and their ligands differ in chronically infected patients versus resolvers should be assessed. A better understanding of the relative contribution of inhibitory receptors (PD-1, CTLA-4, Tim-3) at different stages of disease is required to determine the patient populations that are most likely to benefit from checkpoint blockade therapy.

\section{$B$ cells in the natural history of disease}

Anti-HBV antibodies are used as biomarkers for resolution of HBV infection but the immunological impact of B cells and antibodies on the natural history, resolution or seroconversion in chronic HBV infection have been under-investigated ${ }^{107}$. B cells can produce the immune-suppressive cytokine IL-10 but their depletion can also result in clinical reactivation in both resolved and chronic HBV patients ${ }^{102,108,109}$. Therefore, fundamental questions related to $B$ cell biology, antibody specificity, and neutralizing responses need to be addressed so that $B$ cells can be incorporated more effectively into new immunotherapeutic approaches.

Assays and reagents need to be developed and optimised for the detection and quantification of HBVspecific B cells. ELISPOT assays are needed for accurate and reproducible quantification of HBV-specific antibody producing $B$ cells for research and clinical trial monitoring. Flow cytometry-based reagents are needed to investigate the phenotypic, functional and genetic profile of HBV-specific B cells. Deeper 
analysis of antibody specificity, isotype and functional responses in different stages of HBV infection should be a key area of future research.

\section{Accurately measuring the frequency of infected hepatocytes}

The primary safety concern with immunotherapy in chronic HBV infection is the induction of fulminant hepatitis. Therefore, it is important to know the actual number of infected hepatocytes, the number of hepatocytes expressing viral antigens, and the number of hepatocytes that can be destroyed in an individual patient without causing hepatic deficiency. HBV integration occurs early in cell culture infection but it is unclear how cytolytic vs. non-cytolytic mechanisms will target infected hepatocytes (with replicating HBV) vs those with integration ${ }^{60,110}$. It is imperative to understand the frequency of infected/integrated hepatocytes and how hepatocytes are cleared of HBV or HBsAg to minimize the risk of hepatic decompensation.

In the short term, better methods to quantify infected/integrated hepatocytes in biopsies or through serum biomarkers are needed. An in vivo diagnostic capable of visualizing the infected liver on medical imaging instruments would be an ideal long-term goal. A better understanding of cytolytic clearance of infected cells vs. non-cytolytic inhibition of viral replication in surviving hepatocytes is needed in humans. Different effector functions may be employed by T cells or innate effectors (NK, $\gamma \delta$, MAIT cells) depending on the quantity or phenotype of newly infected/persistently infected/integrated hepatocytes. The development of less invasive technologies based on Fine Needle Aspiration (FNA) instead of liver biopsies will help in understanding these interactions as these will be important to maximizing antiviral efficacy and minimizing potential toxicity.

\section{Standardization of immune-monitoring in clinical trials}

Standardization of immune monitoring during clinical trials is a monumental and necessary task. To improve consistency of immune monitoring between different sites, we propose the development of centrally curated and widely available HBV peptide libraries and tetramers. Coupled to these would be validated protocols for elispot and flow cytometry staining. This would help promote consistent $\mathrm{T}$ cell monitoring.

Sampling during clinical trials for immunological analysis will be critical to improve and advance immune-based therapies. Blood and serum will remain most accessible. Adoption of FNA should be considered where possible to allow for intrahepatic sampling and single cell analyses ${ }^{111}$. Timing is key, as innate immune modulators will have rapid responses whereas $T$ and $B$ cell responses will require months of follow-up. Comparison of positive responses to the drug/vaccine in chronic HBV patients should not only be gauged against baseline responses alone. The magnitude of responses in chronic patients should be compared to Phase I data in healthy individuals or immune responses detected in resolved HBV patients whenever possible. This will provide a clearer assessment of immunogenicity in chronic HBV patients. Immune monitoring in early stage drug development should focus on a broader assessment of immunity - high frequency populations, immune profiling, ELISPOT with large peptide pools rather than attempts at fine specificity. Even negative data is useful and will promote progress and innovation.

\section{Future of immunotherapy}

Just as we are now seeing an expansion of drug targets specific to the virus (entry inhibitors, capsid inhibitors, RNAi and RNA destabilizers), expansion of our knowledge in key areas related to immune failure and reconstitution will expand the breadth of potential immune-based therapies. Identifying the inflection points of immune exhaustion for restoration of $T$ and $B$ cell immunity will improve specificity and reduce toxicity. Checkpoint inhibitors that are currently tested in phase I trials for their 
potential to restore $\mathrm{HBV}$-specific $\mathrm{CD} 8+\mathrm{T}$ cell function offer a promsing perspective for $\mathrm{HBV}$ immunotherapy. However, as discussed above, important questions need to be addressed in future trials about the extent to which T cells can be restored, the dose of anti-PD-1 antibodies, the selection of patients likely to respond based on biomarkers or the disease stage and the risk of side effects due to tissue damage by restored T cells. In this context, it will also be important to determine the efficacy of combination therapies, e.g. checkpoint inhibitors with different antiviral therapies or therapeutic vaccinations, as has been shown to be effective in pre-clinical animal models ${ }^{112}$. For therapies targeting innate immunity, separating antiviral efficacy from inflammation with pattern recognition receptor agonists could improve their therapeutic index. In addition to refining immunotherapy approaches, pushing forward with strategies to engineer antiviral immunity hold promise. $T$ cell receptor (TCR) and chimeric antigen receptor (CAR) gene therapies circumvent the need for restoration ${ }^{42,113-117}$. However, whether long-term engraftment of genetically engineered $T$ cells specific for HBV is needed to maintain control of viral spread from infected cells that escape elimination, similar to resolved patients, has yet to be addressed. Each of these immunotherapeutic strategies should be considered and investigated in the context of combination therapy. Rationally pairing antiviral and immunotherapeutic drugs based on complimentary mechisms of action will hopefully ensure potent antiviral effects with elimination of infected hepatocytes and improve HBV cure rates.

\section{Strategy 3. Coordinated clinical studies to advance HBV cure.}

\section{Collaborative studies required}

While the pharmaceutical industry will develop novel drugs and evaluate them in clinical trials, collaborations with clinical scientists outside of industry will be instrumental to the success of drug development, by facilitating clinical studies, characterizing correlates of "cure", refining treatment endpoints and identifying the best patients for clinical trials according to the mode of action (MoA) of the tested drugs.

\section{Using currently available drugs.}

There is emerging evidence that the HBV disease "time-clock" commences ticking earlier than previously appreciated. This is demonstrated by the finding of integrated HBV DNA in infected hepatocytes within a few days after viral infection in vitro ${ }^{118}$ and in patients during the so-called "immune tolerant" stage of HBV natural history ${ }^{110}$. There is also increasing evidence that HBV DNA integrations are associated with liver cancer ${ }^{119}$, and it remains to be determined whether early initiation of treatment would reduce the likelihood of progression to HCC by preventing integration, inflammation and cell turn-over, and in turn clonal expansion of hepatocytes harbouring integrated sequences.

The identification and characterization of the virological, immunological and other host correlates or determinants of HBV cure would be of utmost importance to guide the clinical development of future curative regimens for patient selection, monitoring of treatment with novel biomarkers, and design of clinical trials according to patient characteristics and MoA of the tested treatments. A repository of serum samples from patients who have resolved their HBV infection, including HBsAg loss patients and those exhibiting immune control (anti-HBs), with appropriate matched controls prior to resolution, should be established and made accessible to researchers across the globe. This would generate considerable statistical power, permitting investigation of serum biomarkers associated with HBV resolution, such as HBsAg levels, HBcrAgs, and circulating HBV RNA. For some samples, matching liver biopsy material and PBMCs should be obtained, enabling direct comparison of cccDNA (from liver samples) and immune responses (from PBMCs) with HBV serum markers in these CHB patients who lost HBsAg either spontaneously or with currently available treatments. 
There is also an urgent need for centralised repositories of HBV-related materials that are readily accessible to HBV researchers globally, similar to resources available to colleagues in the HIV field. Critical to this will be quality assurance of the samples, and the availability of matching clinical data. This repository could be accessed by basic researchers, clinicians, biotechnology and pharmaceutical companies, to facilitate studies and development of new drugs.

A representative list of reagents required needs to be developed by the HBV community and some of the reagents are shown in Box 4: 


\section{Conclusion}

Now is the time for development and implementation of a safe, affordable, widely available cure for CHB for the 292 million people who are affected by HBV globally. To achieve that goal, the following key points must be prioritised urgently (Box 5).

HBV research funding has for too long been woefully inadequate and this must be addressed. New research programs targeting the cccDNA reservoir and stimulating the host immune response in a safe and durable manner must be a high priority for researchers, foundations and governments. We support the recent ROI call from the NIH for "Research to Advance HBV Cure: HIV/HBV CoInfection and HBV Mono-infection", for projects on HBV or HIV/HBV immunology, virology and therapeutics ${ }^{120}$. ICE-HBV seeks to achieve its goals by fostering collaborative partnerships with researchers, clinicians, the pharmaceutical industry and a range of stakeholders, including communities affected by CHB.

We invite HBV researchers and researchers from outside the HBV field, as well as industry, research stakeholders, and members of the HBV-affected community to join forces with ICE-HBV in a global effort to discover, develop, test and implement HBV cure strategies, to help ensure that the WHO goal of HBV elimination as public health threat by 2030 is achieved.

* ICE HBV Working Group Members 


\section{References}

1. Polaris Observatory C. Global prevalence, treatment, and prevention of hepatitis B virus infection in 2016: a modelling study. Lancet Gastroenterol Hepatol 2018; 3(6): 383-403.

2. WHO. Hepatitis B Fact Sheet, 2017.

3. Stanaway JD, Flaxman AD, Naghavi $M$, et al. The global burden of viral hepatitis from 1990 to 2013: findings from the Global Burden of Disease Study 2013. Lancet 2016.

4. Chisari FV, Ferrari C. Hepatitis B virus immunopathogenesis. Annu Rev Immunol 1995; 13: 29-60.

5. Grossi G, Vigano M, Loglio A, Lampertico P. Hepatitis B virus long-term impact of antiviral therapy nucleot(s)ide analogues (NUCs). Liver Int 2017; 37 Suppl 1: 45-51.

6. Estimates of Funding for Various Research, Condition, and Disease Categories (RCDC), 2017.

7. O'Hara GA, McNaughton AL, Maponga T, et al. Hepatitis B virus infection as a neglected tropical disease. PLoS Negl Trop Dis 2017; 11(10): e0005842.

8. Revill P, Testoni B, Locarnini S, Zoulim F. Global strategies are required to cure and eliminate HBV infection. Nat Rev Gastroenterol Hepatol 2016; 13(4): 239-48.

9. Yan $\mathrm{H}$, Zhong $\mathrm{G}, \mathrm{Xu} \mathrm{G}$, et al. Sodium taurocholate cotransporting polypeptide is a functional receptor for human hepatitis $B$ and D virus. eLife 2012; 1: e00049.

10. Nassal M. HBV cccDNA: viral persistence reservoir and key obstacle for a cure of chronic hepatitis B. Gut 2015; 64(12): 1972-84.

11. Newbold JE, Xin H, Tencza M, et al. The covalently closed duplex form of the hepadnavirus genome exists in situ as a heterogeneous population of viral minichromosomes. J Virol 1995; 69(6): 3350-7.

12. Bock CT, Schwinn S, Locarnini S, et al. Structural organization of the hepatitis B virus minichromosome. J Mol Biol 2001; 307(1): 183-96.

13. Messageot $F$, Salhi S, Eon P, Rossignol JM. Proteolytic processing of the hepatitis B virus e antigen precursor. Cleavage at two furin consensus sequences. J Biol Chem 2003; 278(2): 891-5.

14. EASL. EASL 2017 Clinical Practice Guidelines on the management of hepatitis B virus infection. J Hepatol 2017; 67(2): 370-98.

15. Michalak TI, Pasquinelli C, Guilhot S, Chisari FV. Hepatitis B virus persistence after recovery from acute viral hepatitis. J Clin Invest 1994; 93(1): 230-9.

16. Rehermann B, Ferrari C, Pasquinelli C, Chisari FV. The hepatitis B virus persists for decades after patients' recovery from acute viral hepatitis despite active maintenance of a cytotoxic $\mathrm{T}$ lymphocyte response. Nat Med 1996; 2(10): 1104-8.

17. Werle-Lapostolle B, Bowden S, Locarnini S, et al. Persistence of cccDNA during the natural history of chronic hepatitis B and decline during adefovir dipivoxil therapy. Gastroenterology 2004; 126(7): 1750-8.

18. Seetharam A, Perrillo R, Gish R. Immunosuppression in Patients with Chronic Hepatitis B. Curr Hepatol Rep 2014; 13: 235-44.

19. World, Health, Organisation. GLOBAL HEALTH SECTOR STRATEGY ON VIRAL HEPATITIS2016-2021TOWARDS ENDING VIRAL HEPATITIS: World Health Organisation, 2016.

20. Lazarus JV, Block T, Brechot $\mathrm{C}$, et al. The hepatitis B epidemic and the urgent need for cure preparedness. Nat Rev Gastroenterol Hepatol 2018; 15(9): 517-8.

21. Nayagam S, Thursz M, Sicuri E, et al. Requirements for global elimination of hepatitis B: a modelling study. The Lancet infectious diseases 2016; 16(12): 1399-408.

22. Zoulim F, Locarnini $\mathrm{S}$. Hepatitis $\mathrm{B}$ virus resistance to nucleos(t)ide analogues. Gastroenterology 2009; 137(5): 1593-608 e1-2. 
23. Belloni L, Allweiss L, Guerrieri F, et al. IFN-alpha inhibits HBV transcription and replication in cell culture and in humanized mice by targeting the epigenetic regulation of the nuclear cccDNA minichromosome. J Clin Invest 2012; 122(2): 529-37.

24. Wieland SF, Eustaquio A, Whitten-Bauer C, Boyd B, Chisari FV. Interferon prevents formation of replication-competent hepatitis B virus RNA-containing nucleocapsids. Proc Natl Acad Sci U S A 2005; 102(28): 9913-7.

25. Gill US, Peppa D, Micco L, et al. Interferon Alpha Induces Sustained Changes in NK Cell Responsiveness to Hepatitis B Viral Load Suppression In Vivo. PLoS Pathog 2016; 12(8): e1005788.

26. Maini MK, Gehring AJ. The role of innate immunity in the immunopathology and treatment of HBV infection. J Hepatol 2016; 64(1 Suppl): S60-S70.

27. Maini MK, Peppa D. NK cells: a double-edged sword in chronic hepatitis B virus infection. Frontiers in immunology 2013; 4: 57.

28. Kramvis A. Genotypes and genetic variability of hepatitis B virus. Intervirology 2014; 57(34): 141-50.

29. Chen CJ, lloeje UH, Yang HI. Long-term outcomes in hepatitis B: the REVEAL-HBV study. Clin Liver Dis 2007; 11(4): 797-816, viii.

30. Yuen MF, Wong DK, Fung J, et al. HBsAg Seroclearance in chronic hepatitis B in Asian patients: replicative level and risk of hepatocellular carcinoma. Gastroenterology 2008; 135(4): 1192-9.

31. Zeisel MB, Lucifora J, Mason WS, et al. Towards an HBV cure: state-of-the-art and unresolved questions--report of the ANRS workshop on HBV cure. Gut 2015; 64(8): 1314-26.

32. Lok AS, Zoulim F, Dusheiko G, Ghany MG. Hepatitis B cure: From discovery to regulatory approval. Hepatology 2017; 66(4): 1296-313.

33. Thimme R, Wieland $S$, Steiger $C$, et al. CD8(+) T cells mediate viral clearance and disease pathogenesis during acute hepatitis B virus infection. J Virol 2003; 77(1): 68-76.

34. Guidotti LG, Rochford R, Chung J, Shapiro M, Purcell R, Chisari FV. Viral clearance without destruction of infected cells during acute HBV infection. Science 1999; 284(5415): 825-9.

35. Rehermann B. Immune responses in hepatitis B virus infection. Semin Liver Dis 2003; 23(1): 21-38.

36. Hosaka $T$, Suzuki $F$, Kobayashi $M$, et al. Long-term entecavir treatment reduces hepatocellular carcinoma incidence in patients with hepatitis B virus infection. Hepatology 2013; 58(1): 98-107.

37. Papatheodoridis GV, Idilman R, Dalekos GN, et al. The risk of hepatocellular carcinoma decreases after the first 5 years of entecavir or tenofovir in Caucasians with chronic hepatitis $B$. Hepatology 2017; 66(5): 1444-53.

38. Sugarman J, Revill P, Zoulim F, et al. Ethics and hepatitis B cure research. Gut 2016.

39. Hepatitis B Foundation: Drug Watch. Available online: http://www.hepb.org/treatmentand-management/drug-watch 2018. http://www.hepb.org/treatment-and-management/drugwatch (accessed October 1, 2018.

40. Blumberg BS, Alter HJ, Visnich S. A "New" Antigen in Leukemia Sera. Jama 1965; 191: 5416.

41. Strick-Marchand $H$, Dusseaux $M$, Darche $S$, et al. A novel mouse model for stable engraftment of a human immune system and human hepatocytes. PLoS One 2015; 10(3): e0119820.

42. Kah J, Koh $\mathrm{S}$, Volz $\mathrm{T}$, et al. Lymphocytes transiently expressing virus-specific $\mathrm{T}$ cell receptors reduce hepatitis B virus infection. J Clin Invest 2017; 127(8): 3177-88.

43. Klumpp K, Shimada T, Allweiss L, et al. Efficacy of NVR 3-778, Alone and In Combination With Pegylated Interferon, vs Entecavir In UPA/SCID Mice With Humanized Livers and HBV Infection. Gastroenterology 2018; 154(3): 652-62 e8. 
44. Lucifora J, Xia $Y$, Reisinger $F$, et al. Specific and nonhepatotoxic degradation of nuclear hepatitis B virus cccDNA. Science 2014; 343(6176): 1221-8.

45. Wu M, Li J, Yue L, et al. Establishment of Cre-mediated HBV recombinant cccDNA (rcccDNA) cell line for cccDNA biology and antiviral screening assays. Antiviral Res 2018; 152: 45-52.

46. Xia Y, Stadler D, Lucifora J, et al. Interferon-gamma and Tumor Necrosis Factor-alpha Produced by $T$ Cells Reduce the HBV Persistence Form, cccDNA, Without Cytolysis. Gastroenterology 2016; 150(1): 194-205.

47. Chisari FV, Mason WS, Seeger C. Virology. Comment on "Specific and nonhepatotoxic degradation of nuclear hepatitis B virus cccDNA". Science 2014; 344(6189): 1237.

48. Xia Y, Lucifora J, Reisinger F, Heikenwalder M, Protzer U. Virology. Response to Comment on "Specific and nonhepatotoxic degradation of nuclear hepatitis B virus cccDNA". Science 2014; 344(6189): 1237.

49. Seeger C, Sohn JA. Complete Spectrum of CRISPR/Cas9-induced Mutations on HBV cccDNA. Mol Ther 2016; 24(7): 1258-66.

50. Bloom K, Ely A, Arbuthnot P. A T7 Endonuclease I Assay to Detect Talen-Mediated Targeted Mutation of HBV cccDNA. Methods Mol Biol 2017; 1540: 85-95.

51. Yang HC, Kao JH. Persistence of hepatitis B virus covalently closed circular DNA in hepatocytes: molecular mechanisms and clinical significance. Emerg Microbes Infect 2014; 3(9): e64.

52. Belloni L, Pollicino T, De Nicola F, et al. Nuclear HBx binds the HBV minichromosome and modifies the epigenetic regulation of cccDNA function. Proc Natl Acad Sci U S A 2009; 106(47): 19975-9.

53. Levrero M, Pollicino T, Petersen J, Belloni L, Raimondo G, Dandri M. Control of cccDNA function in hepatitis B virus infection. J Hepatol 2009; 51(3): 581-92.

54. Lucifora J, Arzberger S, Durantel D, et al. Hepatitis B virus X protein is essential to initiate and maintain virus replication after infection. J Hepatol 2011; 55(5): 996-1003.

55. Pollicino T, Belloni $L$, Raffa $G$, et al. Hepatitis $B$ virus replication is regulated by the acetylation status of hepatitis B virus cccDNA-bound H3 and H4 histones. Gastroenterology 2006; 130(3): 823-37.

56. Guo YH, Li YN, Zhao JR, Zhang J, Yan Z. HBc binds to the CpG islands of HBV cccDNA and promotes an epigenetic permissive state. Epigenetics 2011; 6(6): 720-6.

57. Decorsiere A, Mueller $H$, van Breugel PC, et al. Hepatitis $B$ virus $X$ protein identifies the Smc5/6 complex as a host restriction factor. Nature 2016; 531(7594): 386-9.

58. Livingston CM, Ramakrishnan D, Strubin M, Fletcher SP, Beran RK. Identifying and Characterizing Interplay between Hepatitis B Virus X Protein and Smc5/6. Viruses 2017; 9(4).

59. Murphy CM, XU Y, Li F, et al. Hepatitis B Virus X Protein Promotes Degradation of SMC5/6 to Enhance HBV Replication. Cell Rep 2016; 16(11): 2846-54.

60. Wooddell $\mathrm{Cl}$, Yuen $\mathrm{MF}$, Chan $\mathrm{HL}$, et al. RNAi-based treatment of chronically infected patients and chimpanzees reveals that integrated hepatitis B virus DNA is a source of $\mathrm{HBsAg}$. Sci Transl Med 2017; 9(409).

61. Maepa MB, Ely A, Grayson W, Arbuthnot P. Sustained Inhibition of HBV Replication In Vivo after Systemic Injection of AAVs Encoding Artificial Antiviral Primary MicroRNAs. Mol Ther Nucleic Acids 2017; 7: 190-9.

62. Zhang $X, L u W$, Zheng $Y$, et al. In situ analysis of intrahepatic virological events in chronic hepatitis B virus infection. J Clin Invest 2016; 126(3): 1079-92.

63. Li M, Sohn JA, Seeger C. Distribution of Hepatitis B Virus Nuclear DNA. J Virol 2018; 92(1).

64. Cai D, Wang $X$, Yan $R$, et al. Establishment of an inducible HBV stable cell line that expresses cccDNA-dependent epitope-tagged HBeAg for screening of cccDNA modulators. Antiviral Res 2016; 132: 26-37. 
65. Guo JT, Guo H. Metabolism and function of hepatitis B virus cccDNA: Implications for the development of cccDNA-targeting antiviral therapeutics. Antiviral Res 2015; 122: 91-100.

66. Li F, Cheng L, Murphy CM, et al. Minicircle HBV cccDNA with a Gaussia luciferase reporter for investigating HBV cccDNA biology and developing cccDNA-targeting drugs. Sci Rep 2016; 6: 36483.

67. Thomas E, Liang TJ. Experimental models of hepatitis B and C - new insights and progress. Nat Rev Gastroenterol Hepatol 2016; 13(6): 362-74.

68. Xia Y, Carpentier A, Cheng $X$, et al. Human stem cell-derived hepatocytes as a model for hepatitis B virus infection, spreading and virus-host interactions. J Hepatol 2017; 66(3): 494-503.

69. Kaneko S, Kakinuma S, Asahina $Y$, et al. Human induced pluripotent stem cell-derived hepatic cell lines as a new model for host interaction with hepatitis B virus. Sci Rep 2016; 6: 29358. 70. Sakurai F, Mitani S, Yamamoto T, et al. Human induced-pluripotent stem cell-derived hepatocyte-like cells as an in vitro model of human hepatitis B virus infection. Sci Rep 2017; 7: 45698.

71. Ortega-Prieto AM, Skelton JK, Wai SN, et al. 3D microfluidic liver cultures as a physiological preclinical tool for hepatitis B virus infection. Nat Commun 2018; 9(1): 682.

72. Allweiss L, Volz T, Giersch K, et al. Proliferation of primary human hepatocytes and prevention of hepatitis B virus reinfection efficiently deplete nuclear cccDNA in vivo. Gut 2017.

73. Dusseaux M, Masse-Ranson G, Darche S, et al. Viral Load Affects the Immune Response to HBV in Mice With Humanized Immune System and Liver. Gastroenterology 2017; 153(6): 1647-61 e9.

74. Cui X, Guo JT, Hu J. Hepatitis B Virus Covalently Closed Circular DNA Formation in Immortalized Mouse Hepatocytes Associated with Nucleocapsid Destabilization. J Virol 2015; 89(17): 9021-8.

75. Glebe D, Aliakbari M, Krass P, Knoop EV, Valerius KP, Gerlich WH. Pre-s1 antigendependent infection of Tupaia hepatocyte cultures with human hepatitis B virus. J Virol 2003; 77(17): 9511-21.

76. Walter E, Keist R, Niederost B, Pult I, Blum HE. Hepatitis B virus infection of tupaia hepatocytes in vitro and in vivo. Hepatology 1996; 24(1): 1-5.

77. Burwitz BJ, Wettengel JM, Muck-HausI MA, et al. Hepatocytic expression of human sodiumtaurocholate cotransporting polypeptide enables hepatitis B virus infection of macaques. Nat Commun 2017; 8(1): 2146.

78. Clements JE, Gama L, Graham DR, Mankowski JL, Zink MC. A simian immunodeficiency virus macaque model of highly active antiretroviral treatment: viral latency in the periphery and the central nervous system. Curr Opin HIV AIDS 2011; 6(1): 37-42.

79. Allweiss L, Dandri M. The Role of cccDNA in HBV Maintenance. Viruses 2017; 9(6).

80. Asabe $S$, Wieland SF, Chattopadhyay PK, et al. The size of the viral inoculum contributes to the outcome of hepatitis B virus infection. J Virol 2009; 83(19): 9652-62.

81. Ebert G, Poeck H, Lucifora J, et al. 5' Triphosphorylated small interfering RNAs control replication of hepatitis $B$ virus and induce an interferon response in human liver cells and mice. Gastroenterology 2011; 141(2): 696-706, e1-3.

82. Isogawa M, Robek MD, Furuichi Y, Chisari FV. Toll-like receptor signaling inhibits hepatitis $B$ virus replication in vivo. J Virol 2005; 79(11): 7269-72.

83. Janssen HLA, Brunetto MR, Kim YJ, et al. Safety, efficacy and pharmacodynamics of vesatolimod (GS-9620) in virally suppressed patients with chronic hepatitis B. J Hepatol 2018; 68(3): 431-40.

84. Suresh M, Korolowicz KE, Balarezo M, et al. Antiviral Efficacy and Host Immune Response Induction during Sequential Treatment with SB 9200 Followed by Entecavir in Woodchucks. PLoS One 2017; 12(1): e0169631. 
85. Bengsch B, Martin B, Thimme R. Restoration of HBV-specific CD8+ T cell function by PD-1 blockade in inactive carrier patients is linked to T cell differentiation. J Hepatol 2014; 61(6): 12129.

86. Boni C, Fisicaro P, Valdatta C, et al. Characterization of hepatitis B virus (HBV)-specific T-cell dysfunction in chronic HBV infection. J Virol 2007; 81(8): 4215-25.

87. Fisicaro $\mathrm{P}$, Valdatta $\mathrm{C}$, Massari $\mathrm{M}$, et al. Antiviral intrahepatic T-cell responses can be restored by blocking programmed death-1 pathway in chronic hepatitis B. Gastroenterology 2010; 138(2): 682-93, 93 e1-4.

88. Nebbia G, Peppa D, Schurich A, et al. Upregulation of the Tim-3/galectin-9 pathway of T cell exhaustion in chronic hepatitis B virus infection. PLoS One 2012; 7(10): e47648.

89. Schurich $A$, Khanna $P$, Lopes $A R$, et al. Role of the coinhibitory receptor cytotoxic $T$ lymphocyte antigen-4 on apoptosis-Prone CD8 $T$ cells in persistent hepatitis $B$ virus infection. Hepatology 2011; 53(5): 1494-503.

90. Isogawa M, Chung J, Murata Y, Kakimi K, Chisari FV. CD40 activation rescues antiviral CD8(+) T cells from PD-1-mediated exhaustion. PLoS Pathog 2013; 9(7): e1003490.

91. Maier H, Isogawa M, Freeman GJ, Chisari FV. PD-1:PD-L1 interactions contribute to the functional suppression of virus-specific CD8+ T lymphocytes in the liver. J Immunol 2007; 178(5): 2714-20.

92. Schurich $A$, Pallett $L$, Lubowiecki $M$, et al. The third signal cytokine IL-12 rescues the antiviral function of exhausted HBV-specific CD8 T cells. PLoS Pathog 2013; 9(3): e1003208.

93. Gehring AJ. New treatments to reach functional cure: Rationale and challenges for emerging immune-based therapies. Best Pract Res Clin Gastroenterol 2017; 31(3): 337-45.

94. Pallett LJ, Davies J, Colbeck EJ, et al. IL-2(high) tissue-resident T cells in the human liver: Sentinels for hepatotropic infection. J Exp Med 2017; 214(6): 1567-80.

95. Stegmann KA, Robertson $F$, Hansi $N$, et al. CXCR6 marks a novel subset of Tbet(lo)Eomes(hi) natural killer cells residing in human liver. Sci Rep 2016; 6: 26157.

96. Boeijen LL, Hoogeveen RC, Boonstra A, Lauer GM. Hepatitis B virus infection and the immune response: The big questions. Best Pract Res Clin Gastroenterol 2017; 31(3): 265-72.

97. Rehermann B, Chang KM, McHutchinson J, et al. Differential cytotoxic T-lymphocyte responsiveness to the hepatitis B and C viruses in chronically infected patients. J Virol 1996; 70(10): 7092-102.

98. Knolle PA, Thimme R. Hepatic immune regulation and its involvement in viral hepatitis infection. Gastroenterology 2014; 146(5): 1193-207.

99. Das $\mathrm{A}$, Hoare $\mathrm{M}$, Davies $\mathrm{N}$, et al. Functional skewing of the global CD8 $\mathrm{T}$ cell population in chronic hepatitis B virus infection. J Exp Med 2008; 205(9): 2111-24.

100. Fisicaro $P$, Barili $V$, Montanini $B$, et al. Targeting mitochondrial dysfunction can restore antiviral activity of exhausted HBV-specific CD8 T cells in chronic hepatitis B. Nat Med 2017; 23(3): 327-36.

101. Urbani S, Boni C, Amadei B, et al. Acute phase HBV-specific T cell responses associated with HBV persistence after HBV/HCV coinfection. Hepatology 2005; 41(4): 826-31.

102. Das $A$, Ellis $G$, Pallant $C$, et al. IL-10-producing regulatory $B$ cells in the pathogenesis of chronic hepatitis B virus infection. J Immunol 2012; 189(8): 3925-35.

103. $\mathrm{Xu} \mathrm{D}, \mathrm{Fu} \mathrm{J}$, Jin $\mathrm{L}$, et al. Circulating and liver resident CD4+CD25+ regulatory $\mathrm{T}$ cells actively influence the antiviral immune response and disease progression in patients with hepatitis $B$. $J$ Immunol 2006; 177(1): 739-47.

104. Pallett LJ, Gill US, Quaglia A, et al. Metabolic regulation of hepatitis B immunopathology by myeloid-derived suppressor cells. Nat Med 2015; 21(6): 591-600.

105. Peppa D, Gill US, Reynolds G, et al. Up-regulation of a death receptor renders antiviral $T$ cells susceptible to NK cell-mediated deletion. J Exp Med 2013; 210(1): 99-114. 
106. Bertoletti A, Ferrari C. Adaptive immunity in HBV infection. J Hepatol 2016; 64(1 Suppl): S71-S83.

107. Vanwolleghem T, Hou J, van Oord G, et al. Re-evaluation of hepatitis B virus clinical phases by systems biology identifies unappreciated roles for the innate immune response and $B$ cells. Hepatology 2015; 62(1): 87-100.

108. Paul S, Dickstein A, Saxena A, et al. Role of surface antibody in hepatitis B reactivation in patients with resolved infection and hematologic malignancy: A meta-analysis. Hepatology 2017; 66(2): 379-88.

109. Perrillo RP, Gish R, Falck-Ytter YT. American Gastroenterological Association Institute technical review on prevention and treatment of hepatitis $B$ virus reactivation during immunosuppressive drug therapy. Gastroenterology 2015; 148(1): 221-44 e3.

110. Mason WS, Gill US, Litwin S, et al. HBV DNA Integration and Clonal Hepatocyte Expansion in Chronic Hepatitis B Patients Considered Immune Tolerant. Gastroenterology 2016; 151(5): 986-98 e4.

111. Tjwa ET, Zoutendijk R, van Oord GW, et al. Similar frequencies, phenotype and activation status of intrahepatic NK cells in chronic HBV patients after long-term treatment with tenofovir disoproxil fumarate (TDF). Antiviral Res 2016; 132: 70-5.

112. Liu J, Zhang $E, M a ~ Z$, et al. Enhancing virus-specific immunity in vivo by combining therapeutic vaccination and PD-L1 blockade in chronic hepadnaviral infection. PLoS Pathog 2014; 10(1): e1003856.

113. Bohne F, Chmielewski M, Ebert $G$, et al. T cells redirected against hepatitis $B$ virus surface proteins eliminate infected hepatocytes. Gastroenterology 2008; 134(1): 239-47.

114. Gehring AJ, Xue SA, Ho ZZ, et al. Engineering virus-specific T cells that target HBV infected hepatocytes and hepatocellular carcinoma cell lines. J Hepatol 2011; 55(1): 103-10.

115. Koh S, Shimasaki N, Suwanarusk R, et al. A practical approach to immunotherapy of hepatocellular carcinoma using $T$ cells redirected against hepatitis B virus. Mol Ther Nucleic Acids 2013; 2: e114.

116. Krebs K, Bottinger N, Huang LR, et al. T cells expressing a chimeric antigen receptor that binds hepatitis B virus envelope proteins control virus replication in mice. Gastroenterology 2013; 145(2): 456-65.

117. Qasim W, Brunetto M, Gehring AJ, et al. Immunotherapy of HCC metastases with autologous $\mathrm{T}$ cell receptor redirected $\mathrm{T}$ cells, targeting $\mathrm{HBsAg}$ in a liver transplant patient. $J$ Hepatol 2015; 62(2): 486-91.

118. Tu T, Budzinska MA, Vondran FWR, Shackel NA, Urban S. Hepatitis B virus DNA integration occurs early in the viral life cycle in an in vitro infection model via NTCP-dependent uptake of enveloped virus particles. J Virol 2018.

119. Zhao LH, Liu X, Yan HX, et al. Genomic and oncogenic preference of HBV integration in hepatocellular carcinoma. Nat Commun 2016; 7: 12992.

120. NIH. Research to Advance HBV Cure: HIV/HBV Co-Infection and HBV Mono-infection (R01 Clinical Trial Not Allowed). 2018. https://grants.nih.gov/grants/guide/pa-files/PAS-19-

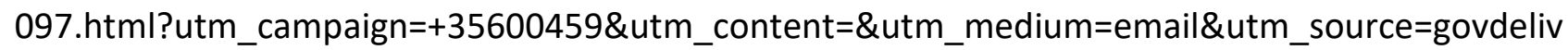
ery\&utm_term=). . 


\section{Lead Authors}

- Pr. Peter A Revill, Victorian Infectious Diseases Reference Laboratory, Royal Melbourne Hospital and Department of Microbiology and Immunology at the Peter Doherty Institute of Infection and Immunity, Melbourne, Australia.

- Pr. Emeritus Francis V. Chisari, M.D., Department of Immunology and Microbial Sciences, The Scripps Research Institute, La Jolla, CA 92037, USA

- Ms. Joan M. Block, Hepatitis B Foundation, Doylestown, PA, USA

- Dr Maura Dandri, 1) I. Medical Clinic, University Medical Center Hamburg-Eppendorf, Hamburg, Germany

- 2) German Centre for Infection Research (DZIF), Hamburg-Lübeck-Borstel partner site, Germany.

- Dr Adam J Gehring, Toronto Centre for Liver Disease, Toronto General Hospital Research Institute, Department of Immunology, University of Toronto, Canada

- A/P Haitao Guo, Department of Microbiology and Immunology, Indiana University School of Medicine Indianapolis, USA

- Pr. Jianming Hu, Department of Microbiology and Immunology, The Pennsylvania State University College of Medicine, USA

- Dr. Harry L.A Janssen, Toronto Centre for Liver Disease, University of Toronto, Canada

- Pr. Anna Kramvis, PhD. Hepatitis Virus Diversity Research Unit, Department of Internal Medicine, School of Clinical Medicine, University of the Witwatersrand, South Africa. ORCID 0000-0001-6006-3765

- Pr. Pietro Lampertico, CRC “A. M. and A. Migliavacca” Center for the Study of Liver Disease, Division of Gastroenterology and Hepatology, Fondazione IRCCS Cà Granda Ospedale Maggiore Policlinico, Università degli Studi di Milano, Milan, Italy

- Pr. Massimo Levrero Cancer Research Center of Lyon (CRCL), Lyon 69008, France; INSERM, U1052, Lyon 69003, France; Hospices Civils de Lyon (HCL), 69002 Lyon, France; Department of Internal Medicine - DMISM, Sapienza University, 00161 Rome, Italy; CLNS@SAPIENZA, Istituto Italiano di Tecnologia (IIT), 00161 Rome, Italy.

- Dr. Wenhui Li, 1. National Institute of Biological Sciences, Beijing, China 2. Tsinghua Institute of Multidisciplinary Biomedical Research,Tsinghua University, Beijing, China

- $\quad$ Pr Seng-Gee Lim, Professor of Medicine, Division of Gastroenterology and Hepatology, Department of Medicine, Yong Loo Lin School of Medicine, National University Health System, National University of Singapore, Singapore

- $\quad$ Dr. T. Jake Liang, NIH, NIDDK, USA

- Pr. Fengmin Lu, Peking university Health Science Center, China

- Ms. M. Capucine Pénicaud, Peter Doherty Institute of Infection and Immunity, Melbourne, Australia. ORCID 0000-0002-2708-8773

- Pr. John E. Tavis, Department of Molecular Microbiology and Immunology, Saint Louis University School of Medicine, St. Louis, USA.

- Prof. Dr. Robert Thimme, Department of Medicine II, Medical Center - University of Freiburg, Germany

- Pr. Fabien Zoulim, INSERM Unit 1052 - Cancer Research Center of Lyon; Hospices Civils de Lyon; Lyon University; Lyon, France

\section{Declaration of interests}

PR reports grants from Gilead Sciences, outside the submitted work. FVC reports personal fees from Gilead Sciences, Avalia Immunotherapies and Vir Biotechnology, outside the submitted work. JB has nothing to disclose. MD reports grants from Roche, personal fees from Gilead Sciences, other from Novira Therapeutics, Humabs BioMed, Hepatera, outside the submitted work. AG reports grants from Gilead Sciences, personal fees from SpringBank Pharmaceuticals, grants from Janssen Pharmaceuticals, personal fees from Aicuris, personal fees from Arbutus, personal fees from VBI, outside the submitted work. HG reports grants from Arbutus Biopharma, grants from Spring Bank Pharmaceuticals and Aligos Therapeutics, personal fees from Assembly Biosciences and Aligos Therapeutics, outside the submitted work. JH reports personal fees from Arbutus, Gilead, Sanofi, grants from Gilead, Roche, outside the submitted work. HLAJ reports grants from AbbVie, Bristol Myers Squibb, Gilead Sciences, Janssen, Medimmune, Merck, Roche., personal fees from AbbVie, Benitec, Bristol Myers Squibb, Gilead Sciences, Janssen, Medimmune, Merck, Roche, Arbutus, Vir Biotechnology Inc., outside the submitted work. AK has nothing to disclose. PL reports personal fees from BMS, Roche, Gilead, GSK, MSD, Janssen, outside the submitted work; ML reports grants and non-financial support from BMS, grants from Contravir, personal fees from Galapagos, personal fees and other from Gilead, personal fees from Arbutus, personal fees and other from Jansen, other from Roche, other from MSD, outside the submitted work. WL has nothing to disclose. SGL reports grants and personal fees from Gilead Sciences, personal fees from Abbvie, 
grants and personal fees from Merck Sharpe and Dohme, grants and personal fees from Abbott Diagnostics, personal fees from Springbank, grants and personal fees from Roche, outside the submitted work. TJL has nothing to disclose. FL has nothing to disclose. CP reports personal fees from Janssen (J\&), outside the submitted work; JT has nothing to disclose. RT has nothing to disclose. FZ reports grants from RocheJanssen, and Evotec, personal fees from Arbutus, personal fees from Gilead, personal fees from Myr Pharma, personal fees from Transgene, personal fees from Vir Biotech, outside the submitted work.

\section{Acknowledgements}

This work was supported by the Australian Academy of Science, France Recherche (ANRS) and the Peter Doherty Institute for Infection and Immunity. This work was supported in part by the intramural research program of NIDDK, $\mathrm{NIH}$ (to BR).

\section{Contributors}

All authors contributed to the conception of this position paper, the drafting of the manuscript, regular reviews and final approval. All agree to be accountable for all aspects of the work. Working drafts for review and comment were compiled by PAR, CP and FZ. MD and HG led the Virology Working Group. AG and RT led the Immunology Working Group. JH and FL led the Tools Working Group. HLAJ, SGL and PL led the Clinical Studies group. PA, AB, KC, J-JC, DG, LG, JF, CF, LJ, DL, ASL, MM, WM, GM, SP, JP, BR, ECS, AT, FVB, FSW, KW, HCW, ZY, MFY were members of the ICE-HBV Virology, Immunology and Tools working Groups. TB, VM and UP chaired the ICE-HBV Stakeholders Consulting Group which provided regular input on the draft in person. CB, MP, SL and RS formed the ICE-HBV Senior Advisors Group which provided detailed input on the draft, in person and by email.

\section{Search strategy and selection criteria}

ICE-HBV has facilitated scientific discussions within and between working groups on virology, immunology, and innovative tools with input from clinical advisors, to identify gaps in HBV cure research and perform the research needed to address these. Together these groups form the ICE-HBV scientific working group, which met in person in April 2017, September 2017 and April 2018 and worked online via Zoom and email to draft the position paper after this. They produced a gap analysis of HBV cure research in English that served a basis for developing the scientific roadmap for HBV cure. ICE-HBV has gathered key stakeholders from around the world and the region to provide input on the scientific roadmap. Two consultations were organised in person in Sao Paulo and Melbourne. 152 stakeholders from 21 countries and 5 continents were consulted.

\footnotetext{
* Full List online http://ice-hbv.org/activities/working-groups/
} 
HBs Ang

Pre-s truncation
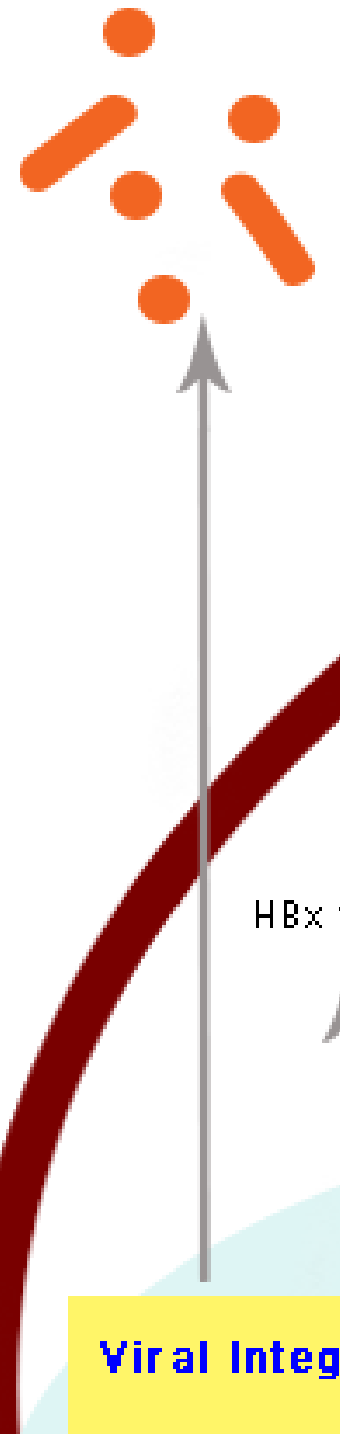

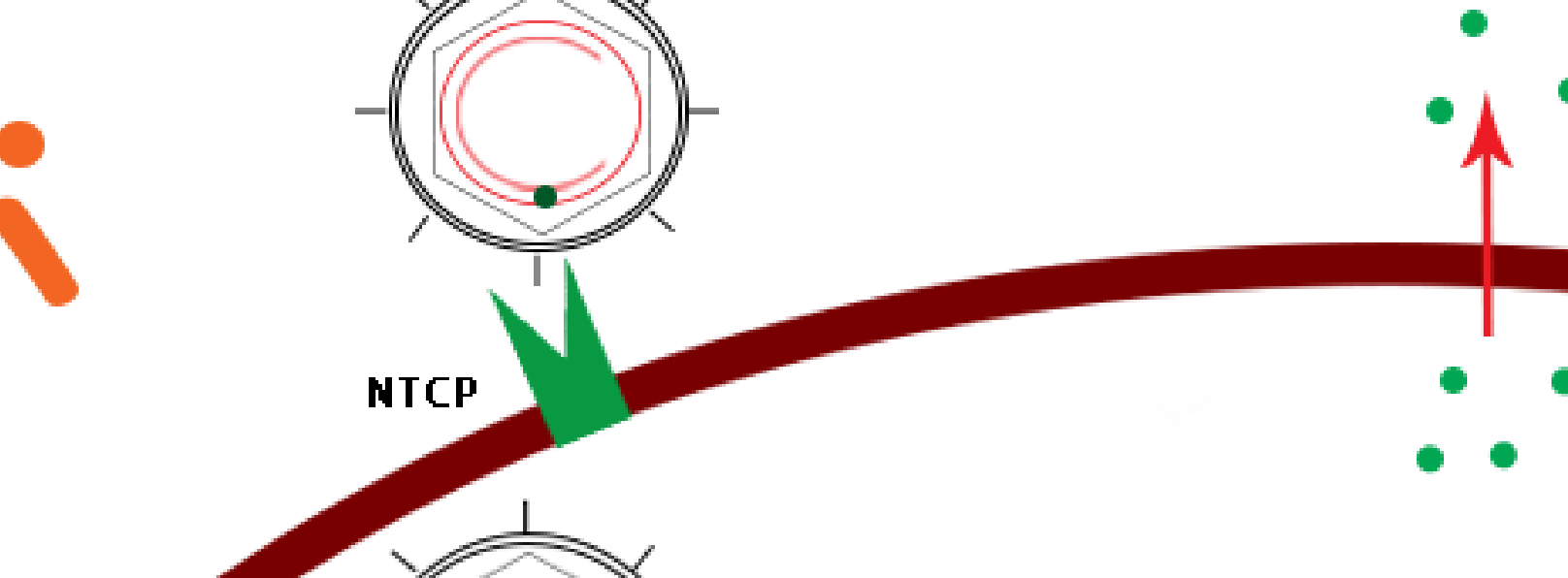

HBEAg

- $\bullet$

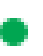

GOLGI

A 4

HBx truncation

$$
1
$$

Viral Integration

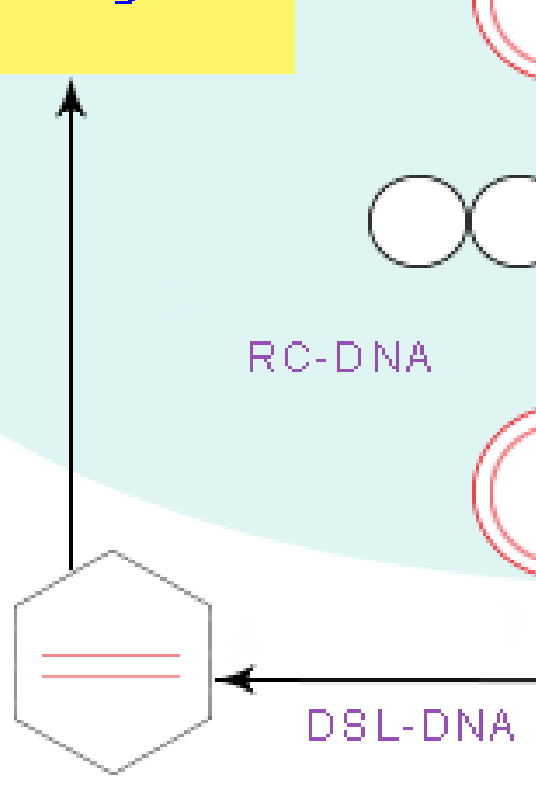

ER

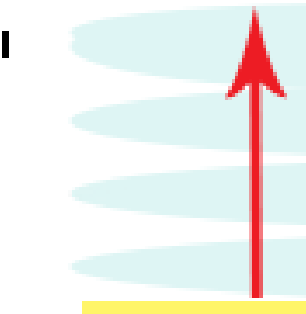

De-envelopment

Nuclear<smiles></smiles>

$\rightarrow$
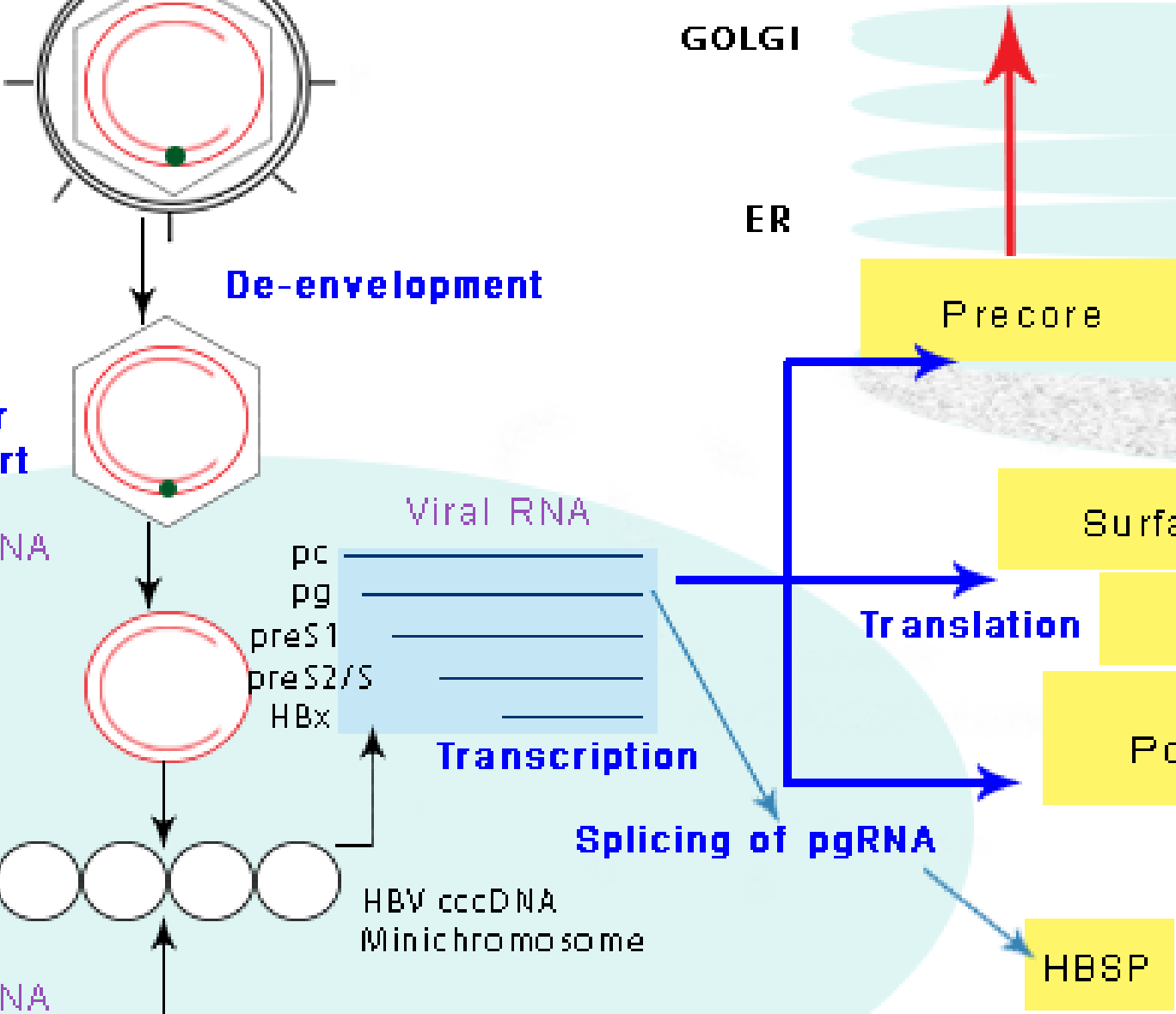

Spherical \& Filamentous HBsigg

Mature HBv virion

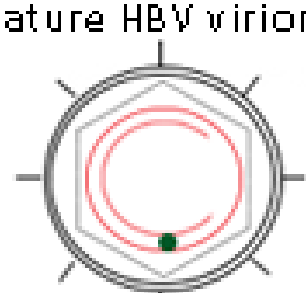

RNA-containing particle

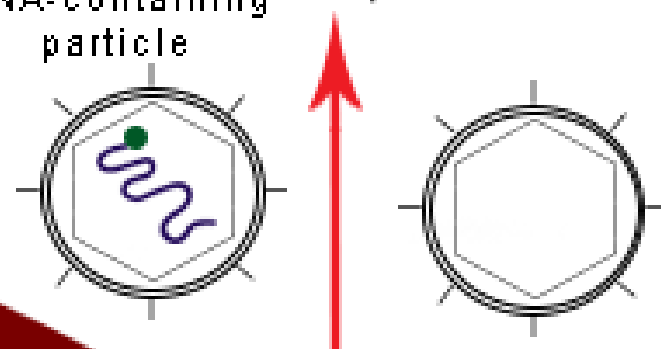

Empty virion

Transport

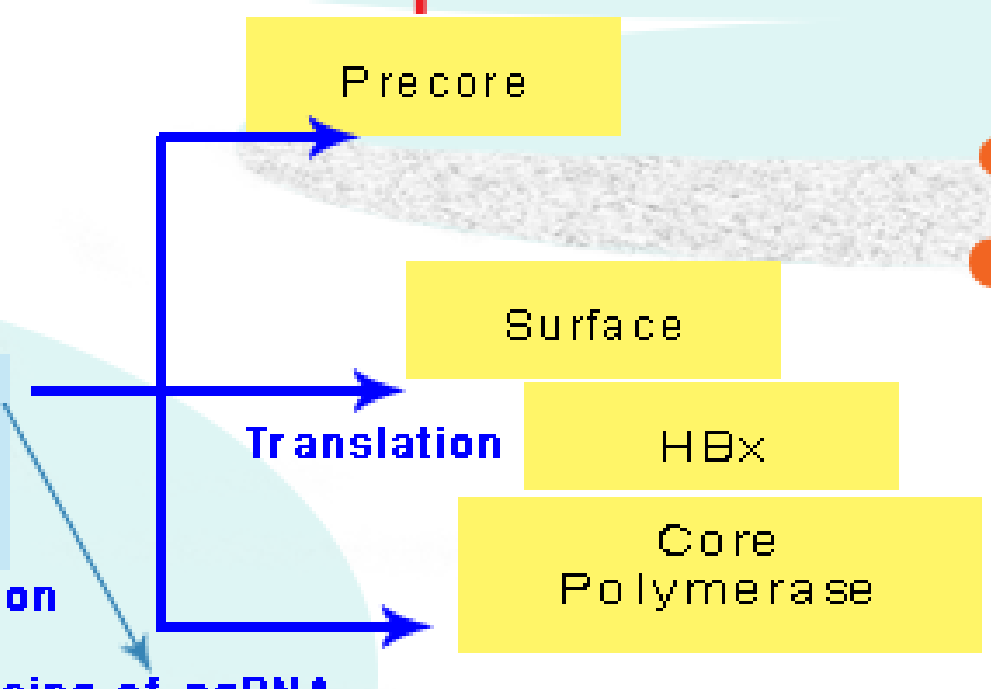

Splicing of pgRNA

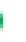
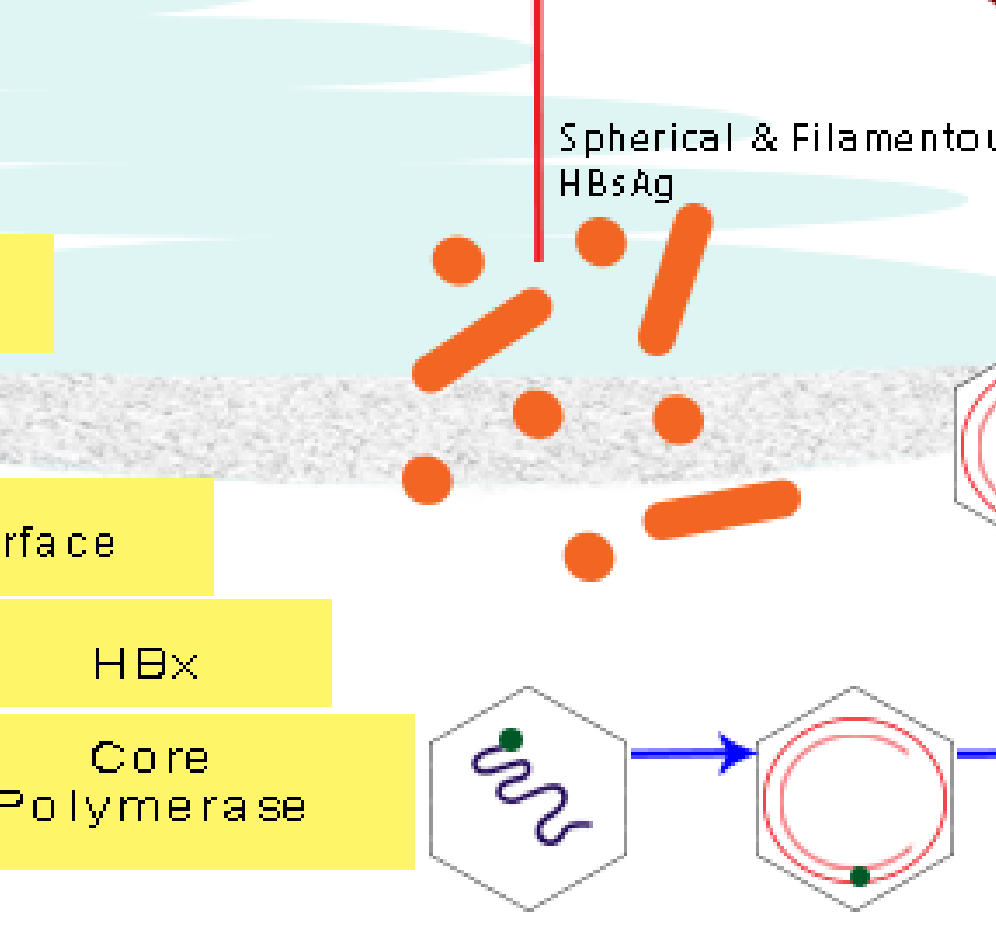

Reverse Transcription
ucleocap sid
Immature HBs Ag

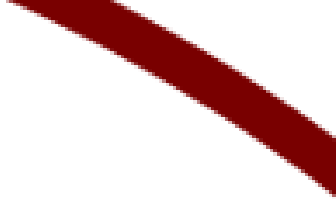




\section{Mechanisms of CD8+ T-cell failure}

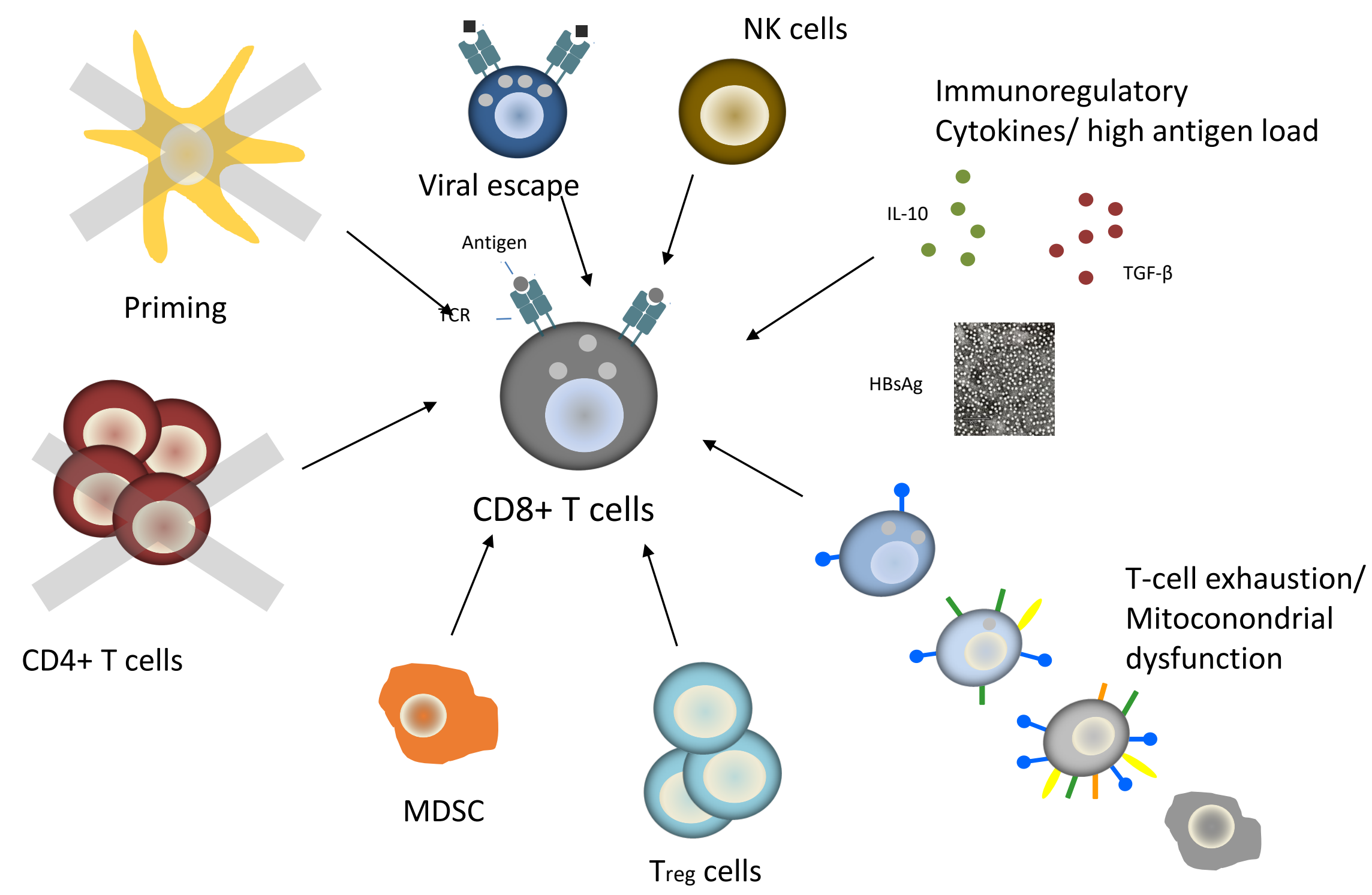

